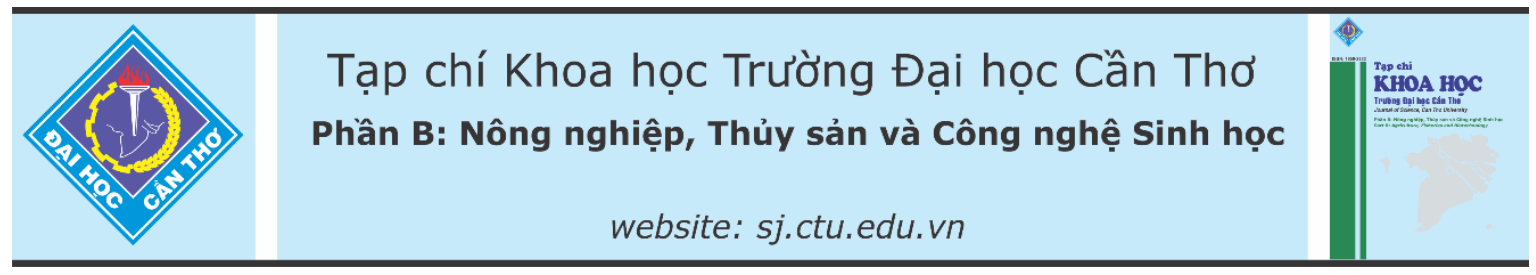

DOI:10.22144/ctu.jvn.2021.050

\title{
ĐẠC ĐIỂM DINH DƯỠNG VÀ SINH TRƯỞNG CỦA CÁ NÂU Scatophagus argus (LINNAEUS, 1776) PHÂN BỐ Ở ĐẦM PHÁ TAM GIANG
}

Nguyễn Văn Huy*, Lê Minh Tuệ, Trần Thị Thu Sương, Nguyễn Phi Nam, Lê Thị Thu An và Nguyễn Tử Minh

Khoa Thủy sản, Trương Đại học Nông Lâm Hué

*Người chịu trách nhiệm về bài viết: Nguyễn Văn Huy (email: huy.nguyen@hueuni.edu.vn)

\section{Thông tin chung:}

Ngày nhận bài: $21 / 09 / 2020$

Ngày nhận bài sưa: 01/03/2021

Ngày duyệt đăng: 28/04/2021

\section{Title:}

Feeding habits and growth characteristics of spotted scat Scatophagus argus (Linnaeus, 1776) in Tam Giang lagoon

\section{Tù khóa:}

Cá nâu, đặc điểm dinh duỡng, đặc điểm sinh truơong, đầm phá Tam Giang

\section{Keywords:}

Feeding habits, growth characteristics, spotted scat, Tam Giang lagoon

\section{ABSTRACT}

The present study aims to determine the feeding habits and growth characteristics of spotted scat Scatophagus argus in Tam Giang lagoon of Thua Thien Hue province. A total of 180 specimens were randomly collected from 7/2018 to 6/2019 and divided into three groups based on the length of fish including: $<8,5 \mathrm{~cm}$; from $8,5-14,0 \mathrm{~cm}$ and $>14,0 \mathrm{~cm}$. The results show that the feeds and feeding habits of spotted scat were different among fish sizes. The stomach content analysis showed a wide variety of foods during their young stage and prefer to consume more plants in the later stage of their development. The group of 8,5-14 cm in length had the highest the fullness of gut, followed by groups $<8,5 \mathrm{~cm}$ and $>14 \mathrm{~cm}$. Analysis of the stomach contents revealed that spotted scat is omnivorous fish, feeding mainly 6 different prey items (e.g., bacillariophyta, chlorophyta, cyanophyta, rhodophyta, zooplankton, zoobenthic, and organic matter). Among these food items, bacillariophyta is abundant in the number of species. The analysis of the lengthweight relationship showed that a intercept was 0.062 whiles exponent $b$ was equal to 2,75 with a correlation coefficient $R^{2}=0,9686$. The value of $b$ was below 3 indicates a negative allometric growth pattern of Scatophagus argus that explains the increment of weight does not in proportionate to its length increment. Condition factor $(K)$ varied from 2,97 to 3,37 reveal the stability of the environment and natural foods for fish in Tam Giang lagoon.

\section{TÓM TÁ́T}

Mục đỉch của nghiên cứu này là xác định được đặc điểm dinh duỡng, thành phần thức ăn tư nhiên, tương quan giữa chiều dài và khối luợng và yếu tố điều kiện của cá nâu phân bố ở đầm phá Tam Giang. Tổng số 180 mẫu cá nâu thu tù tháng 7/2018 đến tháng 6/2019 được chia thành 3 nhóm theo chiều dài toàn thân lần luợt là $<8,5$ $\mathrm{cm}$; tù $8,5-14 \mathrm{~cm} v a ̀$ $>14 \mathrm{~cm}$. Kết quả phân tích chỉ ra rằng thív ăn và tập tính dinh duoõng của cá nâu thay đổi theo nhóm kích thước. Cá ăn tạp ở giai đoạn chiều dài $<8,5 \mathrm{~cm}$; chuyển sang ăn tạp thiên về thưc vật ở nhóm cá có kích thước $>8,5$ $\mathrm{cm}$. Bậc độ no ở nhóm cá có chiều dài $8,5-14 \mathrm{~cm}$ là cao nhất đến nhóm cá $<8,5$ $\mathrm{cm} v a \grave{a}>14 \mathrm{~cm}$. Phân tích thành phần thív ăn trong dạ dày cho thấy cá nâu là loài ăn tạp với 6 nhóm thức ăn chính gồm: tảo silic, tảo luc, tảo lam, tảo đỏ, động vật nổi, động vật đáy và mùn bã hưu co, trong đó, ngành tảo Silic - Bacillariophyta chiếm uu thế về thành phần. Phân tích tưong quan giữa chiều dài và khối lượng của cá nâu cho kết quả hệ số a là 0,062 và số mũ b của phuoong trình 2,75, với hệ số tuoong quan $R^{2}=0,9686$. Giá trị b nhỏ hơn 3 chỉ cho thấy sư sinh truơong không đồng nhất của cá nâu và giải thích sự tăng về khối luợng không tuoong ứng với sư gia tăng về chiều dài. Yếu tố điều kiện (K) thay đổi tù 2,97 đến 3,37 chứng tỏ sư ổn định về môi trường sống và thức ăn tự nhiên của cá ở đầm phá Tam Giang. 


\section{1. ĐẶT VẤN ĐỀ}

Cá nâu Scatophagus argus (Linnaeus, 1776) thuộc giống Scatophagus, bộ cá vược (Perciformes) là loài cá phổ biến trên thế giới do màu sắc sặc sõ với các chấm tròn trên cơ thể và có giá trị dinh dưỡng rất cao (Sivan \& Radhakrishnan, 2011). Vijayan et al. (2016) đã tiến hành phân tích thành phần dinh dưỡng của cá nâu so với một số loài cá biển khác và chứng minh rằng cá nâu có giá trị dinh dưỡng cao, thị của chúng có chứa hàm lượng các amino axit thiết yếu và không thiết yếu cao, đặc biệt thịt của chúng không phát hiện thấy có sự xuất hiện của các loại kim loại nặng $(\mathrm{Pb}, \mathrm{Cd})$ như các loài cá biển khác; nhóm tác giả đã đề xuất rằng đây là loài cá cung cấp thực phẩm an toàn cho nhu cầu của con người.

Thức ăn của cá nâu cũng rất đa dạng, gồm thực vật, tảo, các mảnh vụ hữu cơ và mùn bã hữu cơ. Đây là loài rất linh động về tập tính ăn cũng như khả năng chọn lọc thức ăn, do đó thành phần thức ăn chiếm ưu thế trong ruột của chúng còn phụ thuộc vào tính sẵn có của thức ăn (Sivan \& Radhakrishnan, 2011). Thêm vào đó, Gandhi (2002) cho rằng cá nâu không có một loại thức ăn đặc trưng cho nó, mà nó có thể ăn bất cứ thứ gì có sẵn trong môi trường.

Thức ăn đóng vai trò quan trọng trong quá trình sinh trưởng, phát triển của các loài cá. Đặc điểm dinh dưỡng của các loài cá khác nhau thường không giống nhau. Ngay trong cùng một loài, ở các giai đoạn sinh trưởng khác nhau thì thức ăn của chúng cũng khác nhau. Sự thay đổi này phụ thuộc vào mức độ phát triển của cơ quan tiêu hóa, tập tính bắt mồi và nhu cầu dinh dưỡng của cơ thể. Nghiên cứu về đặc điểm dinh dưỡng của cá qua các giai đoạn sinh trưởng giúp ích trong việc nghiên cứu nuôi vồ thành thục, ương các giai đoạn cá giống. Có nhiều phương pháp để xác định đặc điểm dinh dưỡng của cá, trong đó phân tích tần số xuất hiện loại thức ăn có trong ống tiêu hóa của cá đã trở thành phương pháp phổ biến nhất trong nhiều thập kỷ qua. Mục đích của nghiên cứu này là xác định được đặc điểm dinh dưỡng, thành phần thức ăn tự nhiên, đặc điểm sinh trưởng của cá nâu phân bố ở đầm phá Tam Giang để làm cơ sở cho việc sản xuất giống và nuôi thương phẩm loài cá có giá trị kinh tế này.

\section{PHƯƠNG PHÁP NGHIÊN CÚU}

\subsection{Phương pháp thu mẫu và cố định mẫu}

Mẫu cá nâu được thu thập hằng tháng từ tháng 7/2018 đến tháng 6/2019 tại vùng đầm phá Tam Giang, tỉnh Thừa Thiên Huế, trung bình mỗi tháng thu 15 mẫu. Tổng số mẫu đã tiến hành phân tích là 180 con. Mẫu cá thu được chia thành 3 nhóm dựa vào chiều dài tổng $(\mathrm{cm})$ lần lượt như sau: nhóm cá nhỏ $<8,5 \mathrm{~cm}$ (giai đoạn ương giống), nhóm cá trung bình từ $8,5-14 \mathrm{~cm}$ (giai đoạn nuôi thương phẩm, tiền trưởng thành) và nhóm cá lớn $>14 \mathrm{~cm}$ (bắt đầu thành thục sinh dục). Mẫu được cố định trong dung dịch formol $5 \%$ ngay khi vừa đánh bắt, chuyển về phòng thí nghiệm. Trước khi giải phẫu tách ống tiêu hóa, mẫu được cân khối lượng $(\mathrm{W})$, đo chiều dài tổng $\left(\mathrm{L}_{\mathrm{t}}\right)$, chiều dài ruột $\left(\mathrm{L}_{\mathrm{r}}\right)$ cá cũng được đo để xác định $R L G(L r / L t)$.

\subsection{Phương pháp xác định tính ăn của cá nâu}

\section{Phuoong pháp xác định độ no}

Dựa vào lượng thức ăn chứa trong dạ dày và ruột của cá theo thang 5 bậc (từ bậc 0 đến bậc 4 ) của Lebedev (1946) để xác định độ no, từ đó đánh giá cường độ bắt mồi của cá. Mức độ no của dạ dày được xác định và phân chia các mức độ như ở Bảng 1.

\section{Bảng 1. Phân chia các bậc độ no của cá}

\begin{tabular}{cl}
\hline $\begin{array}{c}\text { Bậc độ } \\
\text { no }\end{array}$ & Tỷ lệ thức ăn trong ruột \\
\hline 0 & Ruột không có thức ăn \\
\hline 1 & $\begin{array}{l}\text { Trong ruột xuất hiện một ít thức ăn, } \\
\text { thành ruột không căng ra và mờ đục. } \\
\text { Trong dạ dày có thể trống. }\end{array}$ \\
\hline 2 & $\begin{array}{l}\text { Thức ăn chiếm khoảng } 1 / 2 \text { chiều dài } \\
\text { ruột, dạ dày hơi phình to, thành dạ } \\
\text { dày không trong suốt }\end{array}$ \\
\hline 3 & $\begin{array}{l}\text { Thức ăn chiếm khoảng } 3 / 4 \text { chiều dài } \\
\text { ruột, thành dạ dày căng ra và có thể } \\
\text { bó chặt lại như một chiếc kẹp }\end{array}$ \\
\hline 4 & $\begin{array}{l}\text { Ruột đầy thức ăn, thành dạ dày trong } \\
\text { suốt, không còn tình trạng bó chặt lại } \\
\text { như một chiếc kẹp }\end{array}$ \\
\hline
\end{tabular}

- Phương pháp xác định tính ăn dựa vào tỷ lệ giữa chiều dài ruột và chiều dài thân

Chỉ số tương quan giữa chiều dài ruột và chiều dài thân (RLG) được xác định theo Nikolsky (1963):

$$
\mathrm{RLG}=\mathrm{L}_{\mathrm{r}} / \mathrm{L}_{\mathrm{t}}
$$

Trong đó: $\mathrm{L}_{\mathrm{r}}$ : Chiều dài ruột $(\mathrm{cm}) ; \mathrm{L}_{\mathrm{t}}$ : Chiều dài toàn thân $(\mathrm{cm})$. Nếu RLG $<1$ cá ăn động vật; nếu 1 $\leq R L G \leq 3$ cá ăn tạp; nếu RLG > 3 cá ăn thực vật.

\subsection{Phương pháp xác định phổ thức ăn}

Mẫu ống tiêu hoá của cá được phân tích tại phòng thí nghiệm Khoa Thuỷ sản, Trường Đại học Nông Lâm, Đại học Huế. Ruột cá được cắt từng 
đoạn rồi cắt theo chiều dọc của ống tiêu hóa đi qua dạ dày, sau đó cho toàn bộ thức ăn vào trong đĩa Peptri. Cho thêm $10 \mathrm{~mL}$ nước rồi lắc nhẹ để thức ăn phân tán đều trên đĩa rồi kiểm tra thành phần thức ăn dưới kính hiển vi có gắn trắc vi thị kính để đo kích thước của mỗi loại thức ăn bắt gặp

Phổ thức ăn được xác định dựa vào phương pháp tần số xuất hiện (frequency of occurrence method) và phương pháp đếm điểm (points numerical method) của Biswas (1993).

Tần số xuất hiện một loại thức ăn được ghi nhận số lần bắt gặp loại thức ăn đó có trong ống tiêu hóa (ruột và dạ dày) và tần số xuất hiện được diễn tả bằng phần trăm $(\%)$ số lần xuất hiện trên tổng số mẫu quan sát. Tần số xuất hiện của thức ăn được tính theo công thức sau:

$$
\% O_{i}=\frac{J_{i}}{P} \times 100
$$

Trong đó: $J i$ là số cá mà trong ống tiêu hóa có chứa thức ăn $i ; P$ là tổng số mẫu cá kiểm tra mà trong ống tiêu hóa có chứa thức ăn.

Thành phần thức ăn được xác định đến giống. Đối với nhóm thực vật phù du thì sử dụng các tài liệu của các tác giả Nguyễn Hữu Đại (1999), Skov et al. (2004) và Tôn Thất Pháp và ctv. (2009). Đối với động vật phù du thì sử dụng các tài liệu của Nguyễn Văn Khôi (2001) và Vũ Ngọc Út và ctv. (2019).

\subsection{Phương pháp xác định tương quan về chiều dài - khối lượng}

Tương quan chiều dài - khối lượng của cá và yếu tố điều kiện có ý nghĩa quan trọng để đánh giá chức năng và tác động sinh thái đối với các loài cá. Thêm vào đó, các hệ số sinh trưởng $a, b$ là rất hữu ích để ước tính khối lượng của từng cá thể từ số liệu về chiều dài; để xác định các chỉ số điều kiện; hình thái của quần thể thuộc các vùng sinh thái khác nhau.
Mối quan hệ giữa chiều dài và khối lượng cá được tính theo công thức Huxley (1924):

$$
\mathrm{W}=\mathrm{aL}^{\mathrm{b}}
$$

Trong đó, $W$ : khối lượng cơ thể cá $(\mathrm{g}) ; L$ : chiều dài toàn thân $(\mathrm{cm}) ; a$ hằng số tăng trưởng ban đầu; $b$ : hệ số tăng trưởng.

Yếu tố điều kiện $(\mathrm{K})$ (condition factor) để phát hiện sự thay đổi về mùa vụ xuất hiện của cá và sự thay đổi này là do sự phong phú về thức ăn. Yếu tố điều kiện được xác định dựa theo phương trình của Worthington and Richard (1930):

$$
\mathrm{K}=\mathrm{W} \times 100 / \mathrm{L}^{3}
$$

Trong đó, $W$ là khối lượng trung bình của cá $(\mathrm{g})$; $L$ là chiều dài trung bình của cá $(\mathrm{cm})$. Yếu tố điều kiện được tính riêng cho từng nhóm cá.

\subsection{Phương pháp xử lý số liệu}

Các số liệu thu được gồm chiều dài, khối lượng, chiều dài ruột, tỷ lệ giữa chiều dài ruột và chiều dài thân, bậc độ no, thành phần thức ăn trong ống tiêu hoá được biểu thị bằng giá trị trung bình và độ lệch chuẩn, phương trình tương quan giữa chiều dài và khối lượng cơ thể, đồ thị tương quan được phân tích và vẽ bằng phần mềm Excel của Microsoft.

\section{KẾT QUẢ VÀ THẢO LUÂN}

\section{1. Đặc điểm dinh dưỡng của cá nâu}

\subsubsection{Cường độ bắt mồi của cá theo nhóm kich thước}

Bảng 2 cho thấy độ no của cá nâu ở cả 3 nhóm kích thước xuất hiện từ bậc 0 đến bậc 4 . Trong đó độ no bậc 2 cao nhất, chiếm 33,6\% so với độ no bậc 3 ; bậc 1; bậc 4 và bậc 0 chiếm tỷ lệ lần lượt là 29,6 $\% ; 20,8 \% ; 8,8 \%$ và $7,2 \%$. Hầu hết các ống tiêu hóa cá đều chứa thức ăn, chứng tỏ chúng bắt mồi khá tích cực. Bậc độ no của cá ở các mẫu khảo sát chủ yếu tập trung ở thang bậc 2 - bậc 3 (thức ăn chiếm $1 / 2-3 / 4$ thể tích ruột) chứng tỏ đây là loài cá bắt mồi tích cực và sự phong phú của thành phần thức ăn tự

\begin{tabular}{|c|c|c|c|c|c|c|c|c|c|c|c|c|}
\hline \multirow{3}{*}{$\begin{array}{l}\text { Nhóm kích thước } \\
\text { (cm) }\end{array}$} & \multicolumn{10}{|c|}{ Bậc độ no } & \multirow[b]{3}{*}{$\mathbf{N}$} & \multirow[b]{3}{*}{$\%$} \\
\hline & \multicolumn{2}{|c|}{$\mathbf{0}$} & \multicolumn{2}{|c|}{1} & \multicolumn{2}{|c|}{2} & \multicolumn{2}{|c|}{3} & \multicolumn{2}{|r|}{4} & & \\
\hline & n & $\%$ & $\mathbf{n}$ & $\%$ & $\mathbf{n}$ & $\%$ & $\mathbf{n}$ & $\%$ & $\mathrm{n}$ & $\%$ & & \\
\hline$<8,5$ & 8 & 13,3 & 13 & 21,7 & 16 & 26,7 & 18 & 30 & 5 & 0,8 & 60 & 33,3 \\
\hline $8,5-14$ & 7 & 10,9 & 13 & 20,3 & 20 & 31,3 & 16 & 25 & 8 & 0,9 & 64 & 35,6 \\
\hline$>14$ & 6 & 10,7 & 12 & 21,4 & 17 & 30,4 & 13 & 23,2 & 8 & 0,10 & 56 & 31,1 \\
\hline Tỷ lệ theo bậc độ no & 21 & 11,67 & 38 & 21,11 & 53 & 29,44 & 47 & 26,11 & 21 & 11,67 & 180 & 100 \\
\hline
\end{tabular}
nhiên trong môi trường.

Bảng 2. Kết quả nghiên cứu về độ no theo nhóm kích thước

n: số mẫu bắt gặp ở các bậc độ no; N là tổng mẫu khảo sát. 
Nhìn chung, cá có xu hướng tăng cường độ bắt mồi ở nhóm kích thước $<8,5 \mathrm{~cm}$ và nhóm kích thước từ $8,5-14 \mathrm{~cm}$, trong đó nhóm kích thước 8,5 $-14 \mathrm{~cm}$ có cường độ bắt mồi cao nhất. Độ no là một chỉ tiêu quan trọng để xác định cường độ bắt mồi của cá và phụ thuộc vào nhiều yếu tố như: chất lượng môi trường nước, điều kiện thời tiết, thời gian trong ngày, môi trường sống, chất lượng thức ăn và trạng thái sinh lí của cá. Cá ở nhóm kích thước > 14 $\mathrm{cm}$ có khả năng bắt mồi giảm lại, điều này liên quan đến sự sinh trưởng và tích lũy cho sinh sản. Trong giai đoạn đầu, cá bắt mồi với cường độ cao, nên cá tăng trưởng nhanh về chiều dài và khối lượng. Cường độ bắt mồi thấp ở cá cũng có thể do sự căng thẳng của cá trong mùa sinh sản (Alam et al., 2015; Mushahida-Al-Noor et al., 2013). Cường độ bắt mồi cũng liên quan đến hệ số điều kiện $K$. Hệ số điều kiện cao cũng có thể do cường độ bắt mồi thấp liên quan đến mùa vụ sinh sản của cá (Mushahida-AlNoor et al., 2013).

\subsubsection{Tưong quan giũa chiều dài ruôt và chiều} dài thân RLG (Relative length of the gut)

Một trong những chỉ số thường được dùng để xác định tính ăn của cá là chỉ số tương quan (RLG) giữa chiều dài ruột $(L r)$ và chiều dài thân $(L t)$. Bảng 3 mô tả về tỷ lệ chiều dài ruột/ chiều dài thân ở 3 nhóm cá khảo sát và Bảng 4 thể hiện về chỉ số RLG của cá nâu cho thấy chỉ số RLG của cá nâu ở các nhóm cá khác nhau là khác nhau. Ở nhóm cá $<8,5$ $\mathrm{cm}$, tỷ lệ RLG trung bình là 2,91. Đối với nhóm cá có kích thước $8,5-14 \mathrm{~cm}$ và $>14 \mathrm{~cm}$ thì tỷ lệ RLG trung bình lần lượt là 3,18 và 3,32 , đều lớn hơn 3 có nghĩa là cá nâu ở nhóm có kích thước lớn hơn 8,5 cm có tập tính ăn tạp thiên về thực vật.

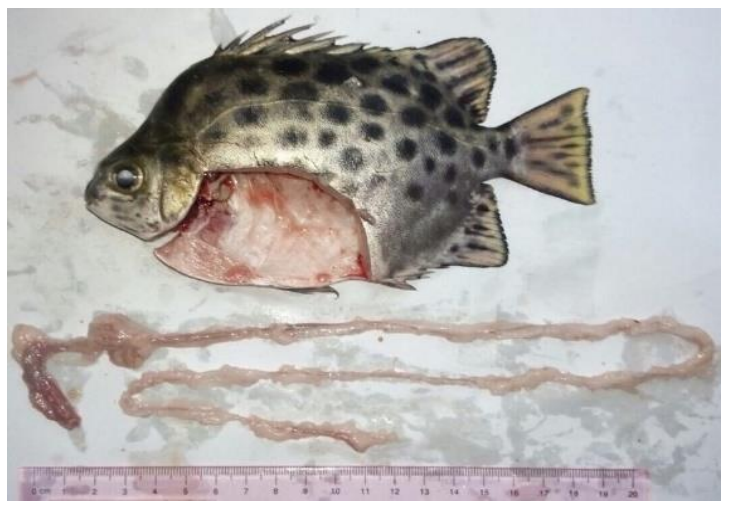

Hình 1. Hình thái cơ thể và ruột cá nâu

Khi kích thước cá càng lớn thì tỷ lệ giữa chiều dài ruột so với chiều dài thân càng tăng, điều đó chứng tỏ cá nâu càng lớn càng có xu hướng ăn tạp thiên về thực vật. Kết quả nghiên cứu này tương đồng với nghiên cứu của Nguyễn Thanh Phương và ctv. (2005) về tỷ lệ chiều dài ruột so với chiều dài thân cá nâu được xác định là 2,88 , kết quả này cho thấy cá nâu thuộc loài cá có tính ăn tạp. Theo Nguyễn Xuân Đồng (2012), cá nâu là loài cá có ống tiêu hoá khá dài, chỉ số RLG trung bình khoảng 2,3 có nghĩa cá nâu là loài ăn tạp thiên về thực vật.

Bảng 3. Tương quan giữa chiều dài ruột và chiều dài thân của cá nâu $(\mathrm{n}=180)$

\begin{tabular}{lcrrr}
\hline Nhóm kích thước $(\mathbf{c m})$ & $\mathbf{n}$ & Chiều dài tổng $(\boldsymbol{L t})$ & Chiều dài ruột $(\boldsymbol{L r})$ & $\boldsymbol{R} \boldsymbol{L} \boldsymbol{G}(\boldsymbol{L r} / \boldsymbol{L} \boldsymbol{t})$ \\
\hline$<8,5$ & 60 & $6,7 \pm 1,6$ & $19,6 \pm 5,4$ & $2,9 \pm 0,3$ \\
$8,5-14$ & 64 & $11,0 \pm 1,7$ & $34,8 \pm 6,6$ & $3,2 \pm 0,4$ \\
$>14$ & 56 & $18,3 \pm 2,4$ & $60,7 \pm 9,6$ & $3,3 \pm 0,3$ \\
\hline
\end{tabular}

n: số mẫu thi nghiệm ở mỗi nhóm kích thước

Như vậy, cá nâu thay đổi đặc điểm dinh dưỡng theo theo nhóm kích thước, lúc còn nhỏ thức ăn chủ yếu là ăn tạp, ở giai đoạn tiền trưởng thành và giai đoạn trưởng thành chúng ăn tạp thiên về thực vật. Kết quả của nghiên cứu này là hoàn toàn phù hợp với công bố của Sivan \& Radhakrishnan (2011) khi cho rằng tảo và các mảnh vụn hữu cơ là những thành phần chính có trong ruột cá nâu, đây là một loài cá ăn tạp; chỉ số RGL thay đổi từ 2,14 đến 3,96 (trung bình là 3,1 ). Tương tự, Nguyễn Thanh Phương và ctv. (2005) cũng đã xác định được tỷ lệ giữa chiều dài ruột/ chiều dài thân của cá nâu phân bố ở Cà Mau là 2,59-2,93 đối với nhóm cá có chiều dài tổng dao động từ $5,1-24,4 \mathrm{~cm}$.

Bảng 4. Chỉ số RLG của cá nâu ở các nhóm kích thước khảo sát $(\mathrm{n}=180)$

\begin{tabular}{llrrr}
\hline $\begin{array}{l}\text { Nhóm kích thước } \\
\text { cá }(\mathbf{c m})\end{array}$ & $\mathbf{n}$ & \multicolumn{2}{c}{ Tỷ lệ chiều dài ruột so với chiều dài thân (RLG) } \\
\cline { 3 - 5 } & & RLG < $\mathbf{1}(\boldsymbol{\%})$ & $\mathbf{1} \leq \mathbf{R L G} \leq \mathbf{3}(\boldsymbol{\%})$ & RLG $>\mathbf{3}(\boldsymbol{\%})$ \\
\hline 8,5 & 60 & 0 & $34(56,7)$ & $26(43,3)$ \\
$8,5-14$ & 64 & 0 & $25(39,0)$ & $39(61,0)$ \\
$>14$ & 56 & 0 & $18(32,1)$ & $38(68,9)$ \\
\hline
\end{tabular}

n: số mẫu thí nghiệm 


\subsubsection{Phổ thức ăn và thành phần thức ăn của cá nâu}

Hình 2 cho thấy phổ thức ăn của cá nâu tập trung chủ yếu vào 4 nhóm, trong đó chủ yếu là thực vật nổi và mùn bã hữu cơ. Bảng 5 mô tả về sự đa dạng về thành phần thức ăn tự nhiên của cá nâu gồm 6 nhóm động thực vật khác nhau gồm (4 ngành tảo, 2 ngành động vật không xương sống) và mùn bã hữu cơ.

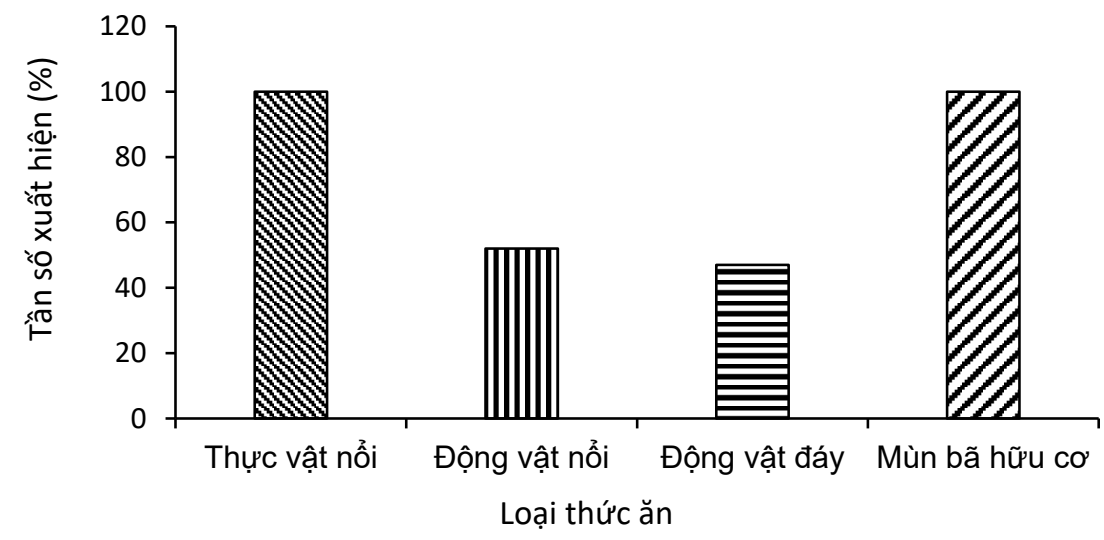

Hình 2. Tần số xuất hiện các loại thức ăn trong ống tiêu hóa cá nâu

Bảng 5. Thành phần và tần số bắt gặp loại thức ăn trong ống tiêu hóa cá nâu

\begin{tabular}{|c|c|c|c|c|c|c|}
\hline & \multicolumn{2}{|c|}{$<8,5 \mathrm{~cm}(\mathrm{n}=60)$} & \multicolumn{2}{|c|}{$8,5-14 \mathrm{~cm}(\mathrm{n}=64)$} & \multicolumn{2}{|c|}{$>14 \mathrm{~cm}(\mathrm{n}=56)$} \\
\hline & Số mẫu (Ji) & Tần số & Số mẫu (Ji) & Tần số & Số mẫu (Ji) & Tần số \\
\hline Tảo Silic - Bacillariophyta & 60 & 100,0 & 64 & 100,0 & 56 & 100,0 \\
\hline Tảo Lục - Chlorophyta & 42 & 69,4 & 50 & 78,3 & 35 & 62,8 \\
\hline Tảo Lam - Cyanophyta & 28 & 46,7 & 24 & 37,2 & 12 & 20,6 \\
\hline Tảo Đỏ - Rhodophyta & 22 & 36,7 & 26 & 40,0 & 29 & 51,7 \\
\hline Động vật nồi & 20 & 32,8 & 16 & 25,0 & 11 & 20,0 \\
\hline Động vật đáy & 18 & 29,4 & 15 & 23,3 & 12 & 21,7 \\
\hline Mùn bã hữu cơ & 60 & 100,0 & 64 & 100,0 & 56 & 100,0 \\
\hline
\end{tabular}

Trong đó, ngành Tảo Silic - Bacillariophyta chiếm ưu thế về thành phần (11 chi), ngành tảo Lam - Cyanophyta có 1 chi, Ngành Tảo Lục Chlorophyta có 3 chi và ngành Tảo Đỏ Rhodophyta có 2 chi. Trong thành phần thức ăn của cá nâu còn gặp các đại diện của 2 ngành động vật không xương sống là Giun đốt - Annelida với đại diện là lớp Giun nhiều tơ Polychaeta với nhóm Giáp xác chân chèo Copepoda đại diện cho ngành Chân khớp - Arthropoda. Thành phần thức ăn gồm cả thực vật lẫn động vật và mùn bã hữu cơ. Trong số những loại thức ăn phân tích được, các ngành tảo có tần số xuất hiện nhiều nhất, đến mùn bã hữu cơ, còn động vật có tần số xuất hiện ít hơn. Điều đó cho thấy, cá nâu thích ăn thực vật hơn động vật.

Hầu hết các nghiên cứu trước đây đều khẳng đình rằng cá nâu loài Scatophagus argus có tính ăn tạp (Das \& Bordoloi, 2014; Gandhi, 2002; Hashim et al., 2014; Nguyễn Xuân Đồng, 2012), thức ăn là mùn bã hữu cơ chiếm đến 97,8\% (Nguyễn Thanh Phương và ctv., 2005). Thức ăn của cá nâu rất đa dạng với sự xuất hiện của các mảnh vụn hữu cơ, tảo đáy, cỏ, giun, rotifer, côn trùng, động vật thân mềm, và động vật phù du. Ở giai đoạn cá con, thức ăn chủ yếu là động vật phù du, thực vật phù du, mảnh vụn hữu cơ (Musikasung et al., 2006). Ở cá trưởng thành, Wongchinawit (2007) đã khẳng định cá nâu thuộc nhóm động vật đáy ăn tạp. Wongchinawit \& Paphavasit (2009) cũng đã chỉ ra rằng dạ dày cá nâu có hình dạng chữ $\mathrm{U}$; ở giai đoạn ấu trùng cá ăn chủ yếu thực vật phù du cỡ nhỏ; ở giai đoạn tiền trưởng thành cá ăn tảo, sinh vật đáy, động vật phù du và mảnh vụn hữu cỡ nhỏ; cá trưởng thành, thành phần thức ăn trong ống tiêu hóa rất đa dạng từ thực vật phù du cỡ nhỏ, sinh vật đơn bào, động vật phù du, sinh vật đáy và mảnh vụn hữu cơ. Trong đó một số nhóm tảo chiếm ưu thế là Coscinodiscus sp., Nitzschia orenzianal, Lyngbia sp., Closteria sp. và Navicula sp..

\subsection{Tương quan giữa chiều dài - khối lượng và yếu tố điều kiện của cá nâu}

Đặc điểm về chiều dài, khối lượng của cá nâu được mô tả chi tiết qua bảng 6 . 
Bảng 6. Chiều dài và khối lượng của quần thể cá nâu

\begin{tabular}{lrrrrrr}
\hline \multirow{2}{*}{$\begin{array}{l}\text { Nhóm kích thước } \\
\text { (cm) }\end{array}$} & \multicolumn{3}{c}{ Chiều dài và khối lượng trung bình } & \multicolumn{3}{c}{$\mathbf{N}$} \\
\hline & Ldd $(\mathbf{c m})$ & $\mathbf{L}_{\mathbf{t b}}$ & $\mathbf{W}_{\mathbf{d d}}(\mathbf{g})$ & $\mathbf{W}_{\mathbf{t b}}$ & $\mathbf{n}$ & $\mathbf{\%}$ \\
\hline$<8,5$ & $2,7-8,4$ & 6,70 & $2,07-19,07$ & 12,15 & 60 & 33,33 \\
$8,5-14$ & $8,5-13,9$ & 10,97 & $19,09-89,27$ & 46,32 & 64 & 35,56 \\
$>14$ & $14,1-22$ & 18,33 & $90,86-400,35$ & 232,47 & 56 & 31,11 \\
\hline Tổng & $2,7-22$ & 36,00 & $2,07-400,35$ & 290,94 & 180 & 100 \\
\hline
\end{tabular}

Ghi chú: Ldd: chiều dài dao động; Ltb: chiều dài trung bình; Wdđ: khối luợng dao động; Wtb: khối luợng trung bình; n: số lương mẫu ở mỗi nhóm; N: tổng mẫu nghiên cưu.

Bảng 6 cho thấy kích thước cá được khai thác ở đầm phá Tam Giang - Cầu Hai dao động trong khoảng $2,7-22,0 \mathrm{~cm}$ và tương ứng với khối lượng $2,1-400,4 \mathrm{~g}$. Quần thể cá nâu được khai thác phân ra làm 3 nhóm kích thước. Nhóm kích thước $<8,5$ $\mathrm{cm}$ có chiều dài dao động $2,7-8,4 \mathrm{~cm}$, khối lượng tương ứng từ 2,1 - 19,1 chiếm $32 \%$. Nhóm kích thước $8,5-14 \mathrm{~cm}$ có số lượng cá thể thu được nhiều nhất, chiếm $36,8 \%$ với chiều dài dao động từ 8,5 -
$13,9 \mathrm{~cm}$, khối lượng tương ứng là 19,1 - 89,3 g. Nhóm cá cuối cùng có kích thước $>14 \mathrm{~cm}$ có chiều dài dao động $14-22 \mathrm{~cm}$, ứng với khối lượng từ 2,1 - 400,4 g chiếm $31,2 \%$.

Quá trình sinh trưởng đặc trưng cho từng loài cá và thể hiện qua mối tương quan giữa chiều dài và khối lượng cơ thể cá được trình bày trong Hình 3 .

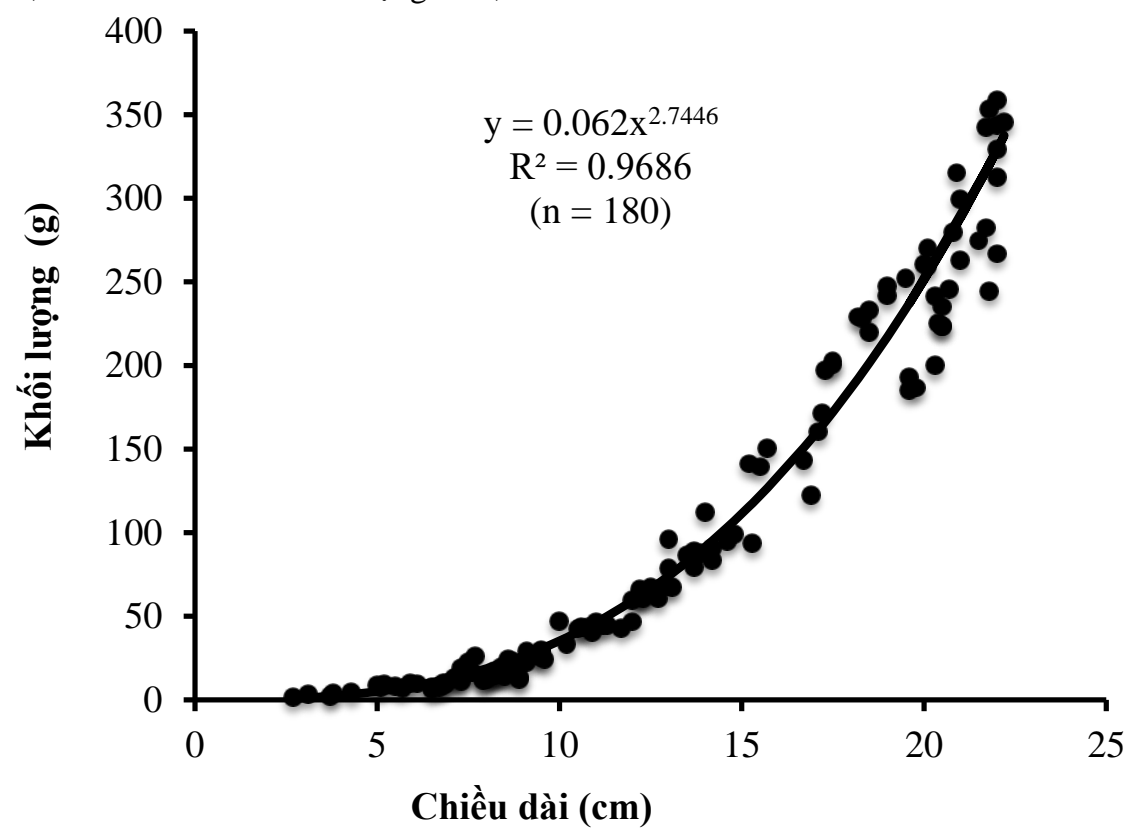

Hình 3. Tương quan giữa chiều dài - khối lượng cá nâu

Phân tích kết quả nghiên cứu chúng tôi thu được các thông số của phương trình tương quan giữa chiều dài và khối lượng của cá nâu là: $W=0,062 x$ $L^{2,7446}$. Hình 3 cho thấy sự tăng trưởng về chiều dài và khối lượng của cá nâu có mối tương quan chặt chẽ với nhau, được thể hiện rất rõ hệ số tương quan $R^{2}=0,9686$ và đây là tương quan thuận rất chặt chẽ, giá trị $b=2,7<3$, chứng tỏ đây là loài cá sinh trưởng không đồng nhất; nghĩa là cá tăng trưởng khối lượng không tương xứng với tăng trưởng về chiều dài cơ thể. Cụ thể ở nhóm cá có kích thước nhỏ nhất $(<8,5$ $\mathrm{cm})$ chiều dài cá tăng nhanh, khối lượng cá tăng chậm; ở giai đoạn lớn hơn (kích thước 8,5 - 14 cm), cá tăng trưởng về chiều dài chậm lại, nhưng tăng trưởng về khối lượng lại tăng lên. Điều này càng thấy rõ hơn ở nhóm kích thước lớn nhất (> $14 \mathrm{~cm}$ ). Giá trị $\mathrm{b}$ trong nghiên cứu này cao hơn so với giá trị được công bố bởi Nguyễn Xuân Đồng (2012) đối với cá Nâu phân bố ở huyện Cần Giờ, TP. Hồ Chí Minh. Theo Hashim et al. (2017) thì sự sinh trưởng của cá nâu không chỉ thay đổi tuỳ thuộc vào giai đoạn phát triển trong vòng đời mà còn phụ thuộc vào nhiều yếu tố, thậm chí thay đổi theo tháng. Điều này có nghĩa là giá trị $b$ của phương trình bị ảnh hưởng 
bởi thức ăn, mùa vụ, nhiệt độ, độ mặn và giai đoạn phát triển.

\subsection{Yếu tố điều kiện $\mathrm{K}$}

Yếu tố điều kiện của các nhóm cá khác nhau được trình bày trong bảng 7 . Hệ số điều kiện $\mathrm{K}$ tăng dần theo sự tăng dần về kích thước của cá.

Bảng 7. Yếu tố điều kiện $(\mathrm{K})$ của cá nâu ở các nhóm kích thước khảo sát $(\mathrm{n}=180)$

\begin{tabular}{lcr}
\hline Nhóm cá $(\mathbf{c m})$ & Số mẫu (n) & Yếu tố điều kiện (K) \\
\hline$<8,5$ & 60 & $2,97 \pm 0,43$ \\
$8,5-14$ & 64 & $3,24 \pm 0,29$ \\
$>14$ & 56 & $3,37 \pm 0,21$ \\
\hline
\end{tabular}

Theo Das and Bordoloi (2014) khuyến cáo phạm vi giá trị $\mathrm{K}(2,9-4,8)$ là phù hợp với cá trưởng thành. Yếu tố điều kiện của mẫu cá nâu trong nghiên cứu hiện tại có sự dao động thấp và có giá trị $\mathrm{K}$ nằm trong phạm vi được khuyến cáo là phù hợp, chứng tỏ môi trường sống của cá có thành phần thức ăn ổn định (Ndiaye et al., 2015). Thêm vào đó, giá trị của ' $\mathrm{K}$ ' bị ảnh hưởng bởi cường độ bắt mồi và sự phát triển của tuyến sinh dục. Giá trị của $\mathrm{K}$ tính toán được trong nghiên cứu này cao hơn so với nghiên cứu của Laghari et al. (2009); Alam and Das (2016). Kết quả này cũng có thể là do sự có sẵn của các loại thức ăn ưa thích trong môi trường và tính cạnh tranh thức ăn thấp của các loài cá đối với nguồn thức ăn theo Alam and Das (2016).

\section{KẾT LUẬN VÀ KIẾN NGH!}

\subsection{Kết luận}

Đặc điểm dinh dưỡng của cá nâu thay đổi theo giai đoạn phát triển, ở giai đoạn cá còn nhỏ, cá nâu là loài ăn tạp, ở giai đoạn cá tiền trưởng thành và trưởng thành cá ăn thực vật là chủ yếu. Thành phần thức ăn của cá nâu rất đa dạng, thuộc 6 nhóm động thực vật khác nhau và mùn bã hữu cơ. Cá nâu là loài cá sinh trưởng không đồng nhất, cá tăng trưởng khối lượng không tương xứng với tăng trưởng về chiều dài cơ thể.

\subsection{Kiến nghị}

Cá nâu là loài đặc sản của đầm phá Tam Giang, tỉnh Thừa Thiên Huế, cần có nhiều nghiên cứu một cách có hệ thống đầy đủ hơn về loài cá nâu này để phát triển sản xuất giống và nuôi thương phẩm đối tượng này.

Nghiên cứu bổ sung về tương quan giữa tuổi cá và kích thước cơ thể để bổ sung đầy đủ thông tin về đặc điểm sinh học của đối tượng này.

\section{LỜI CẢM ƠN}

Đây là kết quả của đề tài khoa học và công nghệ cấp tỉnh được ngân sách nhà nước tỉnh Thừa Thiên Huế đầu tư.

\section{TÀI LIỆU THAM KHẢO}

Alam, A., \& Das S. C. (2016). Feeding and reproductive behaviour of the river catfish Rita rita (Hamilton, 1822) in the river Ganga, India, The Indian Journal of Animal Sciences 86(6): 120-124.

Alam, A., Narinder C., K. D. Joshi, S. Chakraborty, Paramita Banerjee Sawant, Tarkeshwar Kumar \& Anil Sharma. (2015). Maturation profile and fecundity of the exotic in the River Yamuna, India Oreochromis niloticus, Journal of Environmental Biology 36(4), 927-931.

Biswas, S. P. (1993). Manual of methods in fish biology: South Asian Publishere, Pvt.Ltd, New Delhi, 157 pp.

Das, P., A. Khan, S. Mandal, Manna, S. K., \& Ghosh, K. (2014). Distribution of extracellular enzyme-producing bacteria in the digestive tracts of 4 brackish water fish species. Turk. J. Zool., 38, 79-88.

Das M.K. \& Bordoloi S. (2014). Length-weight relationship and condition factor of Lepidocephalichthys goalparensis Pillai and Yazdani, 1976 in Assam, India. J. Appl. Ichthyol. 30, p 246-247.

Gandhi, V. (2002). Studies on the food and feeding of the cultivable butterfish, Scatophagus argus. Journal Marine Biol. Ass. India, 44(1-2), 115-121.

Hashim, M., Abidin, D. A. Z., Das, S. K., \& Mazlan, A. G. (2017). Length-weight relationship, condition factor and TROPH of Scatophagus argus in Malaysian coastal waters. $A A C L$ Bioflux, 10, (297-307).

Hashim, M., D. A. Z. Abidin, S. K. Das, \& Ghaffar., M. A. (2014). Food consumption and digestion time estimation of spotted scat, Scatophagus argus, using X-radiography technique. AIP Conf. Proc., 1614(0), 745-749.

Huxley, L.S. (1924). Constant different growth ratios and their significances, Nature 114, p 895 - 896

Laghari, M.Y, N.T. Narejo, H. Mahesar P.K. Lashari, \& M. Abid. (2009). Length- weigth relationship and condition of indigenous catfish, Rita Rita (Hamilton) from cemented ponds university of Sindh, Jamshoro, Sindh univ, Res. Journal, 41(2), 47 - 52

Lebedev, N. Y. (1946). Elementary populations of fish. Zoologichesky Zhurnal (25), p 121-135.

Musikasung, W., Y. Danayadol, \& Songsangjinda., P. (2006). Stomach content and ecological 
feature of Scatophagus argus (Linnaeus) in Songkhla Lake. Retrieved from Coastal Fisheries Research and Development Bureau: pp.30

Mushahida-Al-Noor, S., Md. Abdus Samad \& N.I.M. Abdus Salam Bhuiyan. (2013). Food and feeding habit of the critically endangered catfish Rita Rita (Hamilton) from Padda river in the north - western region of Banglades. International Journal of Advancement in Reseach and Technology, 2(1), 1- 12

Ndiaye, W., K. Diouf, O. Samba, P. Ndiaye \& J. Panfili. (2015). The Length-Weight Relationship and Condition Factor of white grouper (Epinephelus aeneus, Geoffroy Saint Hilaire, 1817) at the south-west coast of Senegal, West Africa. International Journal of Advanced Research, 3: 145-153.

Nguyễn Hữu Đại. (1999). Thưcc vật thủy sinh: Nxb. Nông nghiệp, TP. Hồ Chí Minh, 290 trang.

Nguyễn Thanh Phương, Võ Thanh Tiến, Trần Thị Thanh Hiền, Phạm Trần Nguyên Thảo \& Lý Văn Khánh. (2004). Nghiên cứu đặc điểm sinh học dinh dưỡng và sinh sản của cá Nâu (Scatophagus argus, Linnaeus 1976). Tap chi Khoa hoc Truòng Đại Học Cần Tho (2), 51-59.

Nguyễn Văn Khôi. (2001). Phân lớp Chân mái chèo - Copepoda, Biển. Động vật chí Việt Nam, Nxb. Khoa học và Kỹ thuật, tập 9: 385 trang.

Nguyễn Xuân Đồng. (2012). Đặc điểm sinh học cơ bản của cá nâu (Scatophagus argus, Linnaeus 1976) thu thập tại huyện Cần Giờ, TP. Hồ Chí Minh. Tạp chí khoa học và phát triển, 10(6), 895-901.

Nikolsky, G. V. (1963). Sinh thái học: Nhà xuất bản Đại học - Trung học chuyên nghiệp (Tài liệu tiếng Việt do Nguyễn Văn Thái, Trần Đình Trọng và Mai Đình Yên dịch), 156 trang

Sivan, G., \& Radhakrishnan, C. K. (2011). Food, Feeding Habits and Biochemical Composition of
Scatophagus argus. Turkish Journal of Fisheries and Aquatic Sciences, 11, 603-608.

Sivan, G., Venketasvaran, K., \& Radhakrishnan, C. K. (2010). Characterization of biological activity of Scatophagus argus venom. Toxicon, 56(6), 914-925.

Skov, J., Tôn Thất Pháp \& Đỗ Thị Bích Lộc. (2004). Ló́p tảo Silic. Opera Botanica, 140, 23-52.

Tôn Thất Pháp, Mai Văn Phô, Ngô Anh \& Nguyễn Việt Thắng. (2009). Thưc vật học: Nxb. Đại Học Huế

Vijayan, Divya K., R. Jayarani, Dilip Kumar Singh, N. S. Chatterjee, Suseela Mathew, B. P. Mohanty, T. V. Sankar \& R. Anandan. (2016). Comparative studies on nutrient profiling of two deep sea fish (Neoepinnula orientalis and Chlorophthalmus corniger) and brackish water fish (Scatophagus argus), The Journal of Basic \& Applied Zoology, 77: 41- 48.

Vũ Ngọc Út, Trương Quốc Phú, và Nguyễn Thị Kim Liên. (2019). Thành Phần Loài và Tiềm Năng Đối Với Nuôi Thủy Sản Ở Đồng Bằng Sông Cưu Long: Nhà Xuất Bản Nông Nghiệp, 134 trang.

Wongchinawit, S. (2007). Feeding ecology of spotted scat Scatophaqus argus, Linnaeus in mangrove forests, Pak Phanang Estuary, Nakhon Si Thammarat province. (Doctoral's Dissertation, Department of Marine Science), Graduate School, Chulalongkorn University.

Wongchinawit, S., \& Paphavasit, N. (2009). Ontogenetic niche shift in the spotted scat, Scatophagus argus, in Pak Phanang estuary, Nakhon Si Thammarat Province, Thailand. Nat. Hist. J. Chulalongkorn Univ, 9(2), 143-169.

Worthington, B.E \& Richard, C.K. (1930). Scientific result of the Cambridge expedition to the east africa lakes No.15, the fishes of lake Rudolf and lake Baringo, J. Lin soc. Zoology, 267, 353 - 389. 